\title{
A Single Strand Conformation Polymorphism Study of CD40 Ligand Efficient Mutation Analysis and Carrier Detection for X-linked Hyper IgM Syndrome
}

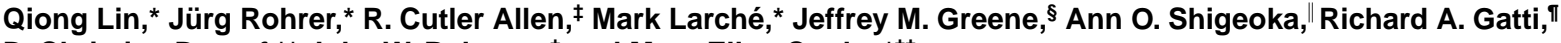 \\ D. Christian Derauf, ${ }^{\star \star}$ John W. Belmont, ${ }^{\ddagger}$ and Mary Ellen Conley ${ }^{\star \neq \neq}$ \\ *Department of Immunology, St. Jude Children’s Research Hospital, Memphis, Tennessee 38105; ${ }^{*}$ Department of Molecular Genetics, \\ Baylor College of Medicine, Houston, Texas 77030; ${ }^{\S}$ Department of Pediatrics, Children's Hospital of Philadelphia, Pennsylvania 19104; \\ "Department of Pediatrics, University of Utah Medical Center, Salt Lake City, Utah 84132; "Department of Pathology, University of \\ California-Los Angeles School of Medicine, Los Angeles, California 90095; **Department of Pediatrics, Kapiolani Medical Center for \\ Women and Children, Honolulu, Hawaii 96826; and ${ }^{\ddagger}$ Department of Pediatrics, The University of Tennessee College of Medicine, \\ Memphis, Tennessee 38103
}

\begin{abstract}
Mutations in the gene for CD40 ligand are responsible for the $\mathrm{X}$-linked form of hyper IgM syndrome. However, no clinical or laboratory findings that reliably distinguish X-linked disease from other forms of hyper IgM syndrome have been reported, nor are there tests available that can be used to confidently provide carrier detection. To identify efficiently mutations in the gene for CD40 ligand, eight pairs of PCR primers that could be used to screen genomic DNA by single strand conformation polymorphism (SSCP) were designed. 11 different mutations were found in DNA from all 13 patients whose activated $\mathrm{T}$ cells failed to bind a recombinant CD40 construct. The exact nature of four of these mutations, a deletion and three splice defects, could not be determined by cDNA sequencing. In addition, SSCP analysis permitted rapid carrier detection in two families in whom the source of the mutation was most likely a male with gonadal chimerism who passed the disorder on to some but not all of his daughters. These studies document the utility of SSCP analysis for both mutation detection and carrier detection in X-linked hyper IgM syndrome. (J. Clin. Invest. 1996. 97:196-201.) Key words: hypergammaglobulinemia, genetics - gene deletion - DNA, mutational analysis - genetic counseling • agammaglobulinemia
\end{abstract}

\section{Introduction}

In 1992 Armitage et al. (1) reported the identification of the murine gene for CD40 ligand. Within $8 \mathrm{mo}$, five groups independently reported that the disorder X-linked hyper IgM syndrome was due to mutations in the human counterpart of this gene (2-6). CD40 ligand, which is also known as gp39 or TRAP $(7,8)$, is a type II transmembrane glycoprotein expressed on the surface of activated $\mathrm{T}$ cells $(1,7,8)$. It plays a critical role in regulation of B cell differentiation. When CD40 ligand binds to its cognate receptor on B cells, CD40, it induces

Address correspondence to Mary Ellen Conley, St. Jude Children's Research Hospital, Department of Immunology, 332 North Lauderdale, Memphis, TN 38105. Phone: 901-495-2576; FAX: 901-495-3107.

Received for publication 29 June 1995 and accepted in revised form 18 September 1995.

J. Clin. Invest.

(C) The American Society for Clinical Investigation, Inc.

0021-9738/96/01/0196/06 \$2.00

Volume 97, January 1996, 196-201
B cell activation; short and long term B cell proliferation; and, in the presence of cytokines, switching from IgM production to $\mathrm{IgG}, \mathrm{IgA}$, and $\mathrm{IgE}$ production (7, 9-11).

Hyper IgM syndrome is characterized by normal or elevated concentrations of serum IgM but low or absent IgG, $\operatorname{IgA}$, and $\operatorname{IgE}(12)$. Patients with the X-linked form of the disease have the onset of infections in the first few years of life and are more likely to have opportunistic infections and/or neutropenia than are patients with autosomal recessive or multifactorial disease. However, these features are not sufficiently specific to permit a definitive diagnosis of X-linked hyper IgM syndrome (13). A variety of approaches have been used to identify patients with mutations in CD40 ligand. We and others have used a recombinant construct consisting of the extracellular domain of CD40 and the Fc fragment of an Ig molecule to indirectly stain activated $\mathrm{T}$ cells from patients who are thought to have X-linked hyper $\operatorname{IgM}$ syndrome $(2-5,13)$. This method is quick, but it requires fresh cells from a living proband. In addition, others have reported that infants and some patients with common variable immunodeficiency have reduced expression of CD40 ligand (14-16). Because carriers of X-linked hyper IgM syndrome demonstrate normal random $\mathrm{X}$ chromosome inactivation in $\mathrm{T}$ cells as well as all other cell populations, $\mathrm{X}$ chromosome inactivation studies cannot be used to confirm a diagnosis or provide carrier detection $(17,18)$.

Most mutations in CD40 ligand have been identified by sequencing cDNA or genomic DNA (2-6, 19-23). Although this approach is quite labor intensive, it has permitted the successful detection of a variety of amino acid substitutions, premature stop codons, splice defects, and small insertions or deletions in the gene. No deletions resulting in changes on Southern blot analysis have been reported. The clarification of the intron/exon structure of CD40 ligand in 1994 (20) laid the groundwork for the use of single strand conformation polymorphism (SSCP) ${ }^{1}$ analysis for screening of genomic DNA for mutations in CD40 ligand. This approach has the advantage that it can be used to provide carrier detection when the proband is no longer living or in families with sporadic $\mathrm{X}$-linked hyper IgM syndrome when the origin of the mutation is not known. A single mutation in CD40 ligand found by SSCP screening has been reported (24); however, it is not clear what proportion of mutations in CD 40 ligand can be detected by SSCP screening.

1. Abbreviations used in this paper: HPRT, hypoxanthine phosphoribosyl transferase; SSCP, single strand conformation polymorphism. 


\section{Methods}

Subjects. The patients in this study have been previously described (13). Briefly, all affected males had the onset of infections before $2 \mathrm{yr}$ of age, and all had serum concentrations of $\operatorname{IgG}$ and $\operatorname{IgA}$ that were more than two standard deviations below the normal mean for age. Activated $\mathrm{T}$ cells from all patients and from some male relatives at risk for having hyper IgM syndrome were analyzed for expression of CD40 ligand using a soluble recombinant CD40 construct as previously described (13).

$P C R$. PCR reactions were carried out in a $20-\mu l$ vol containing 200-400 ng of genomic DNA; $250 \mu \mathrm{M}$ of each dNTP; 25 pmol of each primer, and $1 \mathrm{U} \mathrm{Taq}$ DNA polymerase. For SSCP analysis, $3 \mu \mathrm{Ci}$ of $\left.{ }^{[2} \mathrm{P}\right] \alpha$-dCTP was added to the reaction mix. The samples were denatured at $95^{\circ} \mathrm{C}$ for $5 \mathrm{~min}$ followed by 40 cycles of $95^{\circ} \mathrm{C}$ for $45 \mathrm{~s}$, annealing at the temperature indicated in Table I for $30 \mathrm{~s}, 72^{\circ} \mathrm{C}$ for $30 \mathrm{~s}$ with a final 5-min extension at $72^{\circ} \mathrm{C}$. The primers and conditions used to examine CA repeat polymorphisms at hypoxanthine phosphoribosyl transferase (HPRT) and CD40 ligand were as reported $(25,26)$.

SSCP. SSCP analysis was performed as previously described (27). Labeled amplified DNA was mixed with loading buffer $(95 \%$ formamide, $20 \mathrm{nM}$ EDTA, $0.05 \%$ bromophenol blue, and $0.05 \%$ xylene cyanolFF) in a $1: 5$ ratio, denatured for $7 \mathrm{~min}$ at $85^{\circ} \mathrm{C}$, placed on ice, loaded onto an MDE gel (AT Biochem, Malvern, PA), and electrophoresed at room temperature or at $4^{\circ} \mathrm{C}$ in $0.6 \times \mathrm{TBE}$ at $3-4 \mathrm{~W}$ overnight. Gels were transferred to $3 \mathrm{MM}$ paper (Whatman Inc., Clifton, NJ), dried, and exposed to X-OMAT film (Eastman Kodak Co., Rochester, NY). Autoradiograms were scored for band shifts by two observers.

Cloning and sequencing of mutation-containing exons. PCR products from patients with visible band shifts on SSCP analysis were cloned into TA vector (Invitrogen Corp., San Diego, CA) and sequenced using M13 primers. All mutations were confirmed using a second independent PCR reaction.

Southern blot analysis. DNA was digested with indicated restriction enzymes. Fragments were separated by electrophoresis in a $0.9 \%$ agarose gel and blotted onto nylon filters (Duralon UV Membranes; Stratagene Inc., La Jolla, CA) and analyzed with probes labeled with ${ }^{32} \mathrm{P}$ by random priming.

\section{Results}

Activated $\mathrm{T}$ cells from 17 patients suspected of having X-linked hyper IgM syndrome were indirectly stained with a recombinant construct consisting of the extracellular domain of CD40 and the Fc portion of IgM. Cells from four of the patients demonstrated normal binding to the CD40 construct (13). The cDNA for CD40 ligand was sequenced in each of these four patients and was found to be normal, indicating that these four patients did not have X-linked hyper IgM syndrome. Attempts to sequence the cDNA for CD40 ligand in two overlapping fragments proved to be difficult in three of the remaining patients. In two patients we were unable to amplify the $5^{\prime}$ portion of the gene; in the third patient, the coding sequence appeared to be normal. To overcome these problems and to develop a method which could easily be used to provide carrier detection for X-linked hyper IgM syndrome, we developed a screening evaluation based on SSCP analysis of genomic DNA.

To obtain sufficient DNA sequence to construct appropriate primers, a cosmid containing the CD40 ligand gene was isolated from the Lawrence Livermore $\mathrm{X}$ chromosome library (Livermore, CA) using cDNA from CD40 ligand as a probe. The cosmid was subcloned into Bluescript and primers derived from the cDNA were used to sequence across intron/exon borders and obtain 50-150 bp of sequence both $5^{\prime}$ and $3^{\prime}$ of each exon. Primer pairs were designed to flank each of the coding exons of CD40 ligand plus the associated splice sites (Table I). Because SSCP analysis is most efficient at detecting mutations in PCR products between 90 and 220 bp in length, overlapping PCRs were used for the larger exons. Genomic DNA from the affected males and their female relatives was analyzed. To increase the likelihood of detecting subtle changes in DNA strand migration, gels were run both at room temperature and at $4^{\circ} \mathrm{C}$. Aberrant band patterns were detected in each exon (Fig. 1), and all mutations identified in cDNA sequencing elicited altered band patterns.

We were unable to amplify exon 1 in DNA from Subject 2, one of the three patients for whom we had had difficulties sequencing cDNA. Using a primer $500 \mathrm{bp} 5^{\prime}$ to the first exon and an antisense primer from the $3^{\prime}$ end of the second exon, a $1.5-\mathrm{kb}$ PCR product was derived from the patient's DNA instead of the expected $3.0-\mathrm{kb}$ fragment found in the control. A $1.5-\mathrm{kb}$ deletion including the first exon was confirmed by Southern blot analysis (Fig. 2). It had not been possible to amplify the $5^{\prime}$ portion of the cDNA because the sequence corresponding to the $5^{\prime}$ untranslated region was deleted. The region deleted started $467 \mathrm{bp} 5^{\prime}$ to the transcription start site and included the promoter for CD40 ligand.

Genomic DNA from the second patient who had been difficult to analyze in cDNA studies, Subject 6 , showed an altered band fragment on examination of exon 4 . Sequencing of this exon revealed a $\mathrm{G}$ to $\mathrm{C}$ bp substitution in the +1 position of

Table I. Primer Pairs Used to Screen Genomic DNA for Mutations in CD40 Ligand

\begin{tabular}{|c|c|c|c|c|c|}
\hline Pairs & 5'Primer & 3'Primer & Exon & Size & $\begin{array}{l}\text { Annealing } \\
\text { Temperature }\end{array}$ \\
\hline & & & & $b p$ & \\
\hline 1 & CCAGAAGATACCATTTC & AAGGCTTGTGGTTCATCT & 1 & 207 & $53^{\circ} \mathrm{C}$ \\
\hline 2 & AGCTGTATTCTCCTTCCGAATGAC & СТССТСACAGTTCAGTAAGG & 2 & 155 & $53^{\circ} \mathrm{C}$ \\
\hline 3 & CGATACAGAGATGCAACAG & CAGTTTCCCGATCTAGCA & 2 & 154 & $53^{\circ} \mathrm{C}$ \\
\hline 4 & AGCCCCTGTCAAAATGAC & CCTGATGCAACAACACTG & 3 & 195 & $53^{\circ} \mathrm{C}$ \\
\hline 5 & TAGCCTGACAGTTTTTG & AACATGACTTCGGCATCC & 7 & 156 & $51^{\circ} \mathrm{C}$ \\
\hline 6 & ATGCTCTGCTTCACCTCA & AGGTGACTTGGGCATAGA & $5(\mathrm{~A})$ & 165 & $53^{\circ} \mathrm{C}$ \\
\hline 7 & GGAAACAGCTGACCGTTA & ATTGTTGCCCGCAAGGTT & $5(\mathrm{~B})$ & 191 & $55^{\circ} \mathrm{C}$ \\
\hline 8 & TCTTACTCAGAGCTGCAA & TATGAAGACTCCCAGCGT & $5(\mathrm{C})$ & 225 & $53^{\circ} \mathrm{C}$ \\
\hline
\end{tabular}




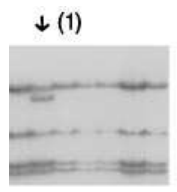

exon 1

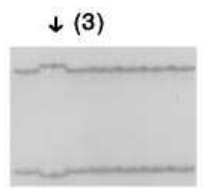

exon 2

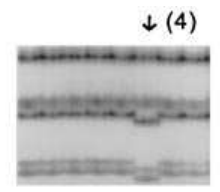

exon 3

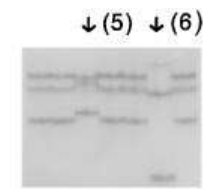

exon 4

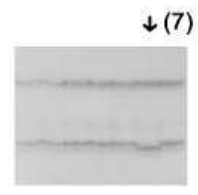

exon $5(A)$

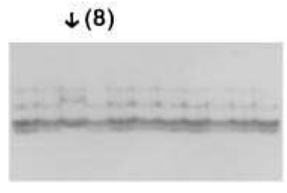

exon $5(B)$

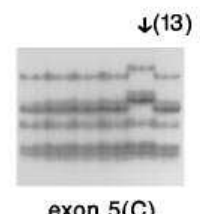

exon $5(C)$
Figure 1. Representative SSCP analyses for each exon of the CD40 ligand gene. The fifth exon was divided into three reactions: A, B, and $\mathrm{C}$. The altered banding pattern seen in exon 1 is from the DNA of the mother of Subject 1 . All other samples demonstrating abnormal bands were from affected males. The subject numbers are shown above the altered pattern. Note that some of the alterations are quite subtle; in DNA from Subject 8, the distance between the two higher bands is slightly decreased.

the intron 4 splice donor site. This patient and his family had previously been described as having a 63-bp deletion (18). Our studies on the $3^{\prime}$ half of the cDNA had shown insertions of 23or 73-bp between nucleotides 429 and 430 (Fig. 3). Analysis of the genomic DNA sequence indicated that the 23- and 71-bp insertions were due to the use of cryptic splice donor sites within intron 4 . Our ability to detect the use of these cryptic splice sites was dependent on the use of a PCR primer that hybridized to a region within exon 4 . When a primer that annealed to sequence in exon 1 was substituted for the exon 4 primer, it was clear that most CD40 ligand transcripts had deleted the 63-bp exon 4, as previously described. Our difficulties in amplifying the $5^{\prime}$ region of the gene were due to the use of an antisense primer, designed in 1992, that bridged the ends of exons 4 and 5.

A splice defect also explained our difficulties in identifying

\section{$\frac{\text { Bam }}{12} \frac{\text { Pst }}{34} \frac{\mathrm{Bgl}}{56}$}

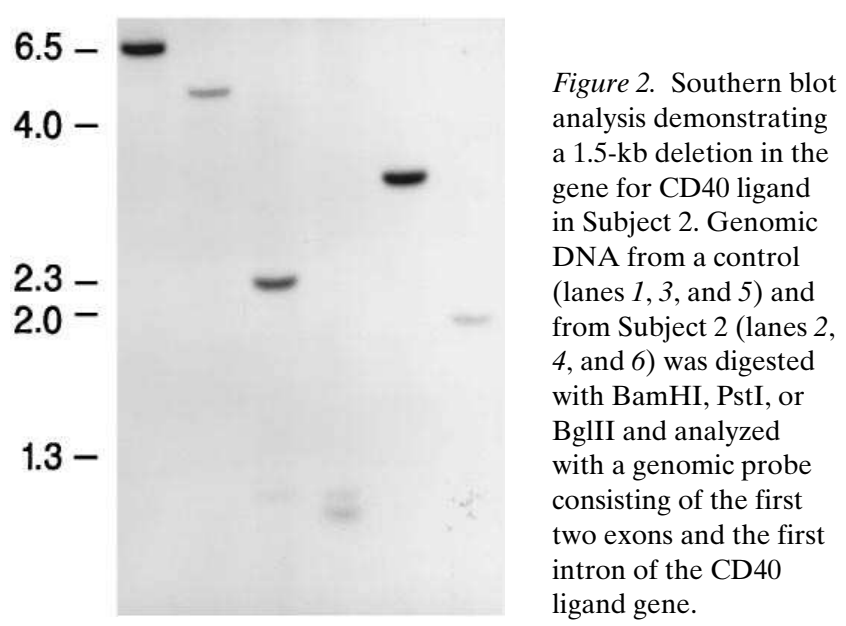

a mutation in the cDNA of Subject 1 , a patient previously reported as having no alterations in the coding regions of the gene for CD40 ligand (2). An abnormality in exon 1 was noted by SSCP analysis. Sequencing of this region demonstrated a $\mathrm{G}$ to $\mathrm{T}$ transversion at the +1 position of the splice donor site for intron 1. Although deletion of the preceding exon is often seen when there are defects in a splice donor site, this mechanism cannot be used when the defect is in the first intron.

The cDNA of Subject 4 demonstrated a deletion of exon 3, suggesting that he too had a mutation resulting in a splice defect. SSCP analysis of the genomic DNA from this patient showed an altered band pattern for exon 3. A G to A transition at the +5 position of the splice donor site for intron 3 was found on sequencing of this region. In Subject 5, a single basepair insertion, a $\mathrm{G}$ insertion, was identified in codon 128 in exon 4.

Table II. Mutations in CD40 Ligand Identified in Subjects from 13 Unrelated Familes

\begin{tabular}{|c|c|c|c|c|c|}
\hline Subject & $\begin{array}{l}\text { Family } \\
\text { history }\end{array}$ & Codon* & Exon & Change & Effect \\
\hline 1 & + & $(52)$ & intron 1 & $\mathrm{G} \rightarrow \mathrm{T}$ & splice defect $(+1)$ \\
\hline 2 & + & $1-52$ & exon 1 /intron 1 & $1.5-\mathrm{kb}$ deletion & no transcript \\
\hline 3 & + & 72 & 2 & $\mathrm{TGC} \rightarrow \mathrm{TGA}$ & Cys $\rightarrow$ Stop \\
\hline 4 & - & $(96)$ & intron 3 & $\mathrm{G} \rightarrow \mathrm{A}$ & splice defect $(+5)$ \\
\hline 5 & + & 128 & 4 & $\mathrm{G}$ insertion & framshift to stop \\
\hline 6 & + & $(136)$ & intron 4 & $\mathrm{G} \rightarrow \mathrm{C}$ & splice defect $(+1)$ \\
\hline 7 & - & 155 & 5 & $\mathrm{CTG} \rightarrow \mathrm{CCG}$ & Leu $\rightarrow$ Pro \\
\hline 8 & - & 155 & 5 & $\mathrm{CTG} \rightarrow \mathrm{CCG}$ & Leu $\rightarrow$ Pro \\
\hline 9 & - & 200 & 5 & $\mathrm{AGA} \rightarrow \mathrm{TGA}$ & Arg $\rightarrow$ Stop \\
\hline 10 & + & 221 & 5 & $\mathrm{CAA} \rightarrow \mathrm{TAA}$ & Gln $\rightarrow$ Stop \\
\hline 11 & - & 227 & 5 & $\mathrm{GGA} \rightarrow \mathrm{GTA}$ & $\mathrm{Gly} \rightarrow \mathrm{Val}$ \\
\hline 12 & - & 232 & 5 & $\mathrm{CAA} \rightarrow \mathrm{TAA}$ & Gln $\rightarrow$ Stop \\
\hline 13 & + & 232 & 5 & $\mathrm{CAA} \rightarrow \mathrm{TAA}$ & $\mathrm{Gln} \rightarrow$ Stop \\
\hline
\end{tabular}

* The codon at the intron/exon border is shown in parentheses in patients with splice defects. 


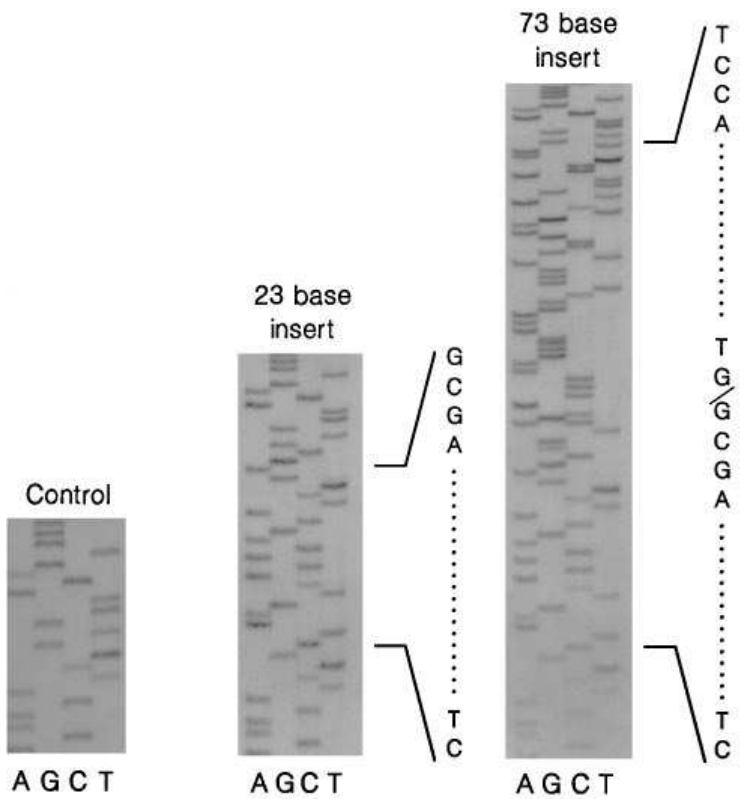

Figure 3. Sequence of cDNA transcripts from Subject 6 showing the insertion of 23 or $73 \mathrm{bp}$. The sequences at the borders of the inserts are shown to the right of the autoradiographs. The $\mathrm{C}$ at the beginning of the inserts represents a $\mathrm{G}$ to $\mathrm{C}$ mutation that ablates the normal splice donor site.
Base pair substitutions resulting in premature stop codons were detected at three different sites in four patients (Table II). Two patients, Subjects 12 and 13, had a $\mathrm{C}$ to $\mathrm{T}$ transition in codon 232 resulting in the substitution of a premature stop codon for the wild-type glutamine. DNA from Subject $13 \mathrm{dem}$ onstrated an additional alteration from the reported sequence in codon 219; a C to A change which would result in the substitution of an arginine for the nonconserved glycine at this site. The presence of two different basepair substitutions 39 nucleotides apart was confirmed by sequencing products from two independent PCRs using different sets of primers, by sequencing DNA from the patient's mother and maternal grandmother, and by using mutation-specific PCR primers. Further SSCP studies demonstrated that the change in codon 219 represented a rare polymorphism seen in 2 of 129 additional unrelated $\mathrm{X}$ chromosomes from Caucasians. The occurrence of the mutation in codon 232 on two different genetic backgrounds, in two unrelated patients from different parts of the country, suggests that the mutations occurred independently rather than as the result of common descent.

Only 3 of the 13 patients with X-linked hyper IgM syndrome had mutations in CD40 ligand that resulted in amino acid substitutions. We have previously reported the mutations in Subjects 7 and 11 in studies using cDNA sequencing (2). Subject 8 , like Subject 7, had a $\mathrm{T}$ to $\mathrm{C}$ transition in codon 155 resulting in the substitution of a proline for the wild-type leu-
A
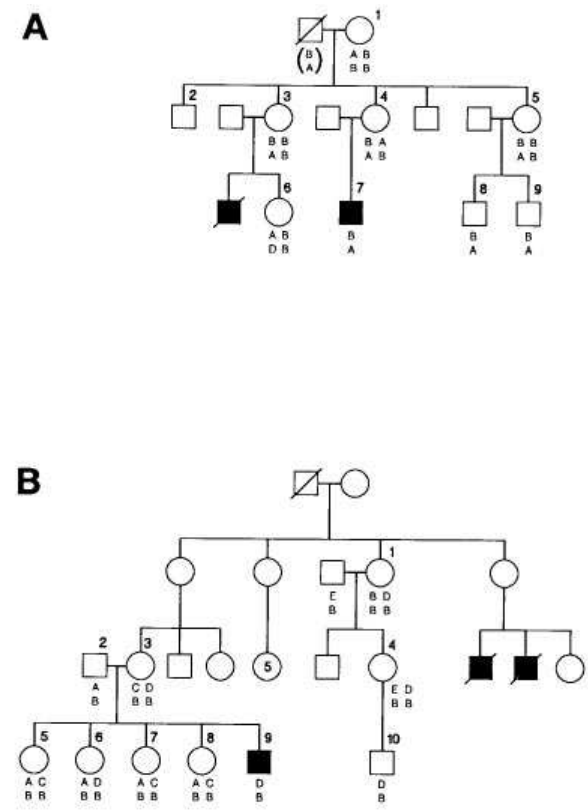

C

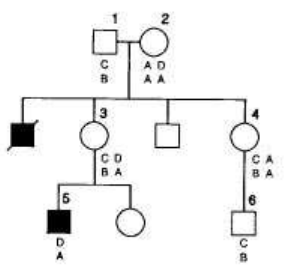

C $123456789 \mathrm{C}$

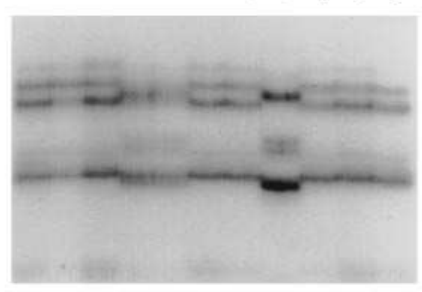

C $12234556789910 \mathrm{C}$

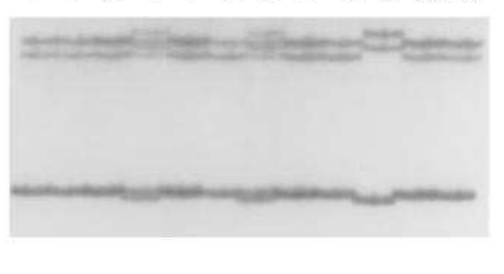

Figure 4. The pedigrees for three families included in this study. The alleles for HPRT (top) and CD40 ligand (bottom) inherited by the family members analyzed are shown below the symbol for the appropriate individual. To the right of each pedigree is the SSCP analysis of each family. The number above each lane corresponds to the number shown above and to the right of the symbol for that individual. The lanes labeled $C$ contain DNA from a control. 
cine. Protein modeling studies have suggested that the leucine at codon 155 is within a beta sheet that is critical to the tertiary structure of the protein (28). A proline at this position would be expected to disrupt the beta sheet. Both patients with the L155P mutation had sporadic disease, one is an African-American child from the south and the other is a Caucasian child of Italian descent from the northeastern United States, suggesting that the mutations occurred as independent events in these two boys.

During our studies on affected boys, we were asked to provide carrier detection for several females at risk. In many families with more than one generation of affected males, it was possible to use the highly polymorphic short tandem repeats within the CD40 ligand gene (25) and the closely linked HPRT gene (29) to provide carrier detection by linkage analysis. However, in several families, the results of linkage analysis were not easy to interpret. Fig. $4 A$ shows the pedigree of Subject 10 , who is indicated in this diagram as individual 8 . The aunt of this subject, who is indicated as individual 5, had two young sons, one with transient neutropenia and the other with low serum IgA; both boys had inherited the same alleles in and around the gene for CD40 ligand as their affected cousin. However, SSCP analysis of exon 5 showed that the mother of these boys was not a carrier of the mutation. Further, sequencing of cDNA for CD40 ligand from individual 9 was identical to the wild-type sequence. The results indicate that the maternal grandfather of the patient passed the mutation on to two of his daughters but not to individual 5 .

In Subject 3's family, shown Fig. 4 B, the mother's cousin, individual 4 , wanted carrier detection during her first pregnancy. Linkage analysis suggested that she had inherited the same alleles at CD40 ligand as her affected nephew. However, SSCP analysis of exon 2 demonstrated that although the patient's mother and one of his sisters were heterozygous for the mutation carried by the patient, neither individual 4 nor her mother were carriers of this mutation. When individual 10 was born, his activated $\mathrm{T}$ cells demonstrated normal binding to the CD40 construct. The results in this family suggest that either the patient's great-grandmother was homozygous for the alleles at CD40 ligand and HPRT or the maternal great-grandfather transmitted the mutation to some but not all of his daughters. The situation in the family of Subject 13, shown in Fig. $4 C$ was simpler. When her nephew was diagnosed as having X-linked hyper IgM syndrome, individual 4 wanted carrier detection. Although this woman had inherited a different allele from her affected nephew at HPRT, the grandmother was uninformative for the more closely linked allele at CD40 ligand. Analysis of SSCP confirmed that individual 4 was not a carrier of X-linked hyper IgM syndrome.

\section{Discussion}

In this paper, we describe the identification of mutations in the gene for CD40 ligand in all 13 patients suspected of having $\mathrm{X}$-linked hyper IgM syndrome. Although most alterations were identified both by cDNA sequencing and SSCP analysis, SSCP was successful in pinpointing the mutations in all patients. The use of SSCP to detect the mutation in Subject 2, who had a $1.5-\mathrm{kb}$ deletion within the gene for CD40 ligand, might be considered indirect. The failure of a single pair of primers to amplify a region of genomic DNA, in this case, exon 1, when all other primer pairs were successful, suggested that the sequence hybridizing to one or both of the primers was absent or mutated. Although SSCP could not be used to track the mutation in the family of Subject 2, Southern blot analysis could be used to follow the altered restriction fragments in females at risk. In all other families included in this study, SSCP could be used to track the mutation.

Providing carrier detection for females at risk of having inherited mutations in the gene for CD40 ligand can be difficult. In families in which several generations are affected, linkage analysis is often helpful, especially if critical individuals are heterozygous for the CA repeat in the $3^{\prime}$ untranslated portion of the CD40 ligand gene. Between 70 and $80 \%$ of women are heterozygous at this locus $(25,30)$; however, several of the mothers or grandmothers included in this study were not informative at this locus. In addition, the results of linkage analysis were misleading in two families shown in Fig. 4 in whom the source of the mutation was most likely a male with gonadal mosaicism. In these families, carrier detection was dependent on a technique that could specifically document the mutation in that family. SSCP performs this function with minimal effort or expense because it does not require sequencing of DNA or identification of a restriction site that is revealed by the mutation.

SSCP and cDNA sequencing can be complementary. The abnormal banding pattern on SSCP analysis focuses attention on the site of the mutation and permits rapid mutation detection. The cDNA sequence demonstrates the functional consequences of that mutation. However, it should be noted that the apparent functional consequences of a mutation may be influenced by the primers chosen to amplify the cDNA. In Subject 6 , a patient with a splice defect, some primers revealed the use of cryptic splice sites; whereas others demonstrated deletion of the exon upstream of the splice donor defect. Some types of mutations cannot be detected by SSCP analysis. A significant proportion of patients with hemophilia A have a DNA inversion that transects the Factor VIII gene $(31,32)$. This chromosomal rearrangement escapes detection by genomic DNA analysis, and it was first recognized by alterations in the cDNA. Some patients with cystic fibrosis have a single basepair substitution in an intron of the CFTR gene (33). This substitution creates a splice donor site and results in the addition of a cryptic exon to the CFTR transcript.

With the exception of the patient with the deletion of exon 1 , the types of mutations identified in our patients were similar to the $\sim 20$ patients reported by others $(2-6,19-24)$. Although we identified 11 different mutations in 13 patients, our data support the hypothesis that there are "hot spots" for mutation in the gene for CD40 ligand (23). Subjects 7 and 8 had the same base pair substitution as did Subjects 12 and 13; neither occurred at $\mathrm{CpG}$ dinucleotides. In addition, Subject 10 had the same $\mathrm{C}$ to $\mathrm{T}$ basepair substitution in codon 221 as a patient reported by Villa et al. (21). These two patients were not of common descent as we could identify the source of mutation in Subject 10. The region around codons 126-129 in exon 4 also appears to be susceptible to alteration, in that four patients, including Subject 5, have mutations in this area $(3,23)$. Although the number of reported mutations in CD40 ligand remains relatively small, our data, and that reported by others, suggest that $>90 \%$ of mutations in this gene occur in the coding regions and in associated splice sites. Further, by using sensitive SSCP conditions most of these mutations can be detected in screening assays. 


\section{Acknowledgments}

We thank Paulina Loo for technical assistance, Janice Mann for secretarial assistance, and Linda Rawlinson for help in preparation of the figures.

These studies were supported in part by grants from the National Institutes of Health AI25129 and National Cancer Institute grant P30 CA21765 and by American Lebanese Syrian Associated Charities.

\section{References}

1. Armitage, R. J., W. C. Fanslow, L. Strockbine, T. A. Sato, K. N. Clifford, B. M. Macduff, D. M. Anderson, S. D. Gimpel, T. Davis-Smith, C. R. Maliszewski, et al. 1992. Molecular and biological characterization of a murine ligand for CD40. Nature (Lond.). 357:80-82.

2. Allen, R. C., R. J. Armitage, M. E. Conley, H. Rosenblatt, N. A. Jenkins, N. G. Copeland, M. A. Bedell, S. Edelhoff, C. M. Disteche, D. K. Simoneaux, et al. 1993. CD40 Ligand gene defects responsible for X-linked hyper-IgM syndrome. Science (Wash. DC). 259:990-993

3. Aruffo, A., M. Farrington, D. Hollenbaugh, X. Li, A. Milatovich, S. Nonoyama, J. Bajorath, L. S. Grosmaire, R. Stenkamp, M. Neubauer, R. L. Roberts, et al. 1993. The CD40 ligand, gp39, is defective in activated T cells from patients with X-linked hyper-IgM syndrome. Cell. 72:291-300.

4. DiSanto, J. P., J. Y. Bonnefoy, J. F. Gauchat, A. Fischer, and G. de Saint Basile. 1993. CD40 ligand mutations in X-linked immunodeficiency with hyperIgM. Nature (Lond.). 361:541-543.

5. Korthauer, U., D. Graf, H. W. Mages, F. Briere, M. Padayachee, S. Malcolm, A. G. Ugazio, L. D. Notarangelo, R. J. Levinsky, and R. A. Kroczek. 1993. Defective expression of T-cell CD40 ligand causes X-linked immunodeficiency with hyper-IgM. Nature (Lond.). 361:539-541.

6. Ramesh, N., R. Fuleihan, V. Ramesh, S. Lederman, M. J. Yellin, S. Sharma, L. Chess, F. S. Rosen, and R. S. Geha. 1993. Deletions in the ligand for CD40 in X-linked immunoglobulin deficiency with normal or elevated IgM (HIGMX-1). Int. Immunol. 5:769-773.

7. Hollenbaugh, D., L. S. Grosmaire, C. D. Kullas, N. J. Chalupny, S. BraeschAndersen, R. J. Noelle, I. Stamenkovic, J. A. Ledbetter, and A. Aruffo. 1992. The human T cell antigen gp39, a member of the TNF gene family, is a ligand for the CD40 receptor: expression of a soluble form of gp39 with B cell co-stimulatory activity. EMBO (Eur. Mol. Biol. Organ.) J. 11:4313-4321.

8. Graf, D., U. Korthäuer, H. W. Mages, G. Senger, and R. A. Kroczek. 1992. Cloning of TRAP, a ligand for CD40 on human T cells. Eur. J. Immunol. 22:3191-3194.

9. Armitage, R. A., B. M. Macduff, M. K. Spriggs, and W. C. Fanslow. 1993. Human B cell proliferation and Ig secretion induced by recombinant CD40 ligand are modulated by soluble cytokines. J. Immunol. 150:3671-3680.

10. Gauchat, J. F., G. Aversa, H. Gascan, and J. E. de Vries. 1992. Modulation of IL-4 induced germline E RNA synthesis in human B cells by tumor necrosis factor- $\alpha$ anti-CD40 monoclonal antibodies or transforming growth factor- $\beta$ correlates with levels of IgE production. Int. Immunol. 4:397-406.

11. Shapira, S. K., D. Vercelli, H. H. Jabara, S. M. Fu, and R. S. Geha. 1992. Molecular analysis of the induction of immunoglobulin E synthesis in human B cells by interleukin 4 and engagement of CD40 antigen. J. Exp. Med. 175:289292.

12. Notarangelo, L. D., M. Duse, and A. G. Ugazio. 1992. Immunodeficiency with hyper-IgM (HIM). Immunodefic. Rev. 3:101-122.

13. Conley, M. E., M. Larché, V. R. Bonagura, A. R. Lawton, III, R. H. Buckley, S. M. Fu, E. Coustan-Smith, H. G. Herrod, and D. Campana. 1994. Hyper IgM syndrome associated with defective CD40-mediated B cell activation. J. Clin. Invest. 94:1404-1409.

14. Nonoyama, S., L. A. Penix, C. P. Edwards, D. B. Lewis, S. Ito, A. Aruffo, C. B. Wilson, and H. D. Ochs. 1995. Diminished expression of CD40 ligand by activated neonatal T cells. J. Clin. Invest. 95:66-75.

15. Durandy, A., G. De Saint Basile, B. Lisowska-Grospierre, J.-F.
Gauchat, M. Forveille, R. A. Kroczek, J.-Y. Bonnefoy, and A. Fischer. 1995. Undetectable CD40 ligand expression on T cells and low B cell responses to CD40 binding agonists in human newborns. J. Immunol. 154:1560-1568.

16. Farrington, M., L. S. Grosmaire, S. Nonoyama, S. H. Fischer, D. Hollenbaugh, J. A. Ledbetter, R. J. Noelle, A. Aruffo, and H. D. Ochs. 1994. CD40 ligand expression is defective in a subset of patients with common variable immunodeficiency. Proc. Natl. Acad. Sci. USA. 91:1099-1103.

17. Hendriks, R. W., M. E. M. Kraakman, I. W. Craig, T. Espanol, and R. K. B. Schuurman. 1990. Evidence that in X-linked immunodeficiency with hyperimmunoglobulinemia $\mathrm{M}$ the intrinsic immunoglobulin heavy chain class switch mechanism is intact. Eur. J. Immunol. 20:2603-2608.

18. Hollenbaugh, D., L. H. Wu, H. D. Ochs, S. Nonoyama, L. S. Grosmaire, J. A. Ledbetter, R. J. Noelle, H. Hill, and A. Aruffo. 1994. The random inactivation of the $\mathrm{X}$ chromosome carrying the defective gene responsible for $\mathrm{X}$ linked hyper IgM syndrome (X-HIM) in female carriers of HIGM1. J. Clin. Invest. 94:616-622.

19. Kroczek, R. A., D. Graf, D. Brugnoni, S. Giliani, U. Korthauer, A. G. Ugazio, and G. Senger. 1994. Defective expression of CD40L ligand on T cells causes "X-linked immunodeficiency with hyper-IgM (HIGM1)." Immunol. Rev. 138:39-59.

20. Villa, A., L. D. Notarangelo, J. P. DiSanto, P. P. Macchi, D. Strina, A. Frattini, F. Lucchini, C. M. Patrosso, S. Giliani, E. Mantuano, et al. 1994. Organization of the human CD40L gene: implications for molecular defects in X-linked hyper-IgM syndrome and prenatal diagnosis. Proc. Natl. Acad. Sci. USA. 91:2110-2114.

21. Villa, A., D. Strina, P. Macchi, M. C. Patrosso, P. Vezzoni, P. A. Tovo, and S. Giliani. 1994. C to T mutation causing premature termination of CD40L at amino acid 221 in a patient affected by hyper-IgM syndrome. Hum. Mutat. 3 : 73-74.

22. Iseki, M., M. Anzo, N. Yamashita, and N. Matsuo. 1994. Hyper-IgM immunodeficiency with disseminated cryptococcosis. Acta Paediatr. 83:780-782.

23. Macchi, P., A. Villa, D. Strina, M. G. Sacco, F. Morali, D. Brugnoni, S. Giliani, E. Mantuano, A. Fasth, B. Andersson, et al. 1995. Characterization of nine novel mutations in the CD40 ligand gene in patients with X-linked hyperIgM syndrome of various ancestry. Am. J. Hum. Genet. 56:898-906.

24. Shimadzu, M., H. Nunoi, H. Terasaki, R. Ninomiya, M. Iwata, S. Kanegasaka, and I. Matsuda. 1995. Structural organization of the gene for CD40 ligand: molecular analysis for diagnosis of X-linked hyper-IgM syndrome. Biochim. Biophys. Acta. 1260:67-72.

25. Allen, R. C., M. K. Springgs, and J. W. Belmont. 1993. Dinucleotide repeat polymorphism in the human CD40 ligand gene. Hum. Mol. Genet. 2:828.

26. Edwards, A., A. Civitello, H. A. Hammond, and C. T. Caskey. 1991.

DNA typing and genetic mapping with trimeric and tetrameric tandem repeats. Am. J. Hum. Genet. 49:746-756.

27. Conley, M. E., M. E. Fitch-Hilgenberg, J. L. Cleveland, O. Parolini, and J. Rohrer. 1994. Screening of genomic DNA to identify mutations in the gene for Bruton's tyrosine kinase. Hum. Mol. Genet. 3:1751-1756.

28. Peitsch, M. C., and C. V. Jongeneel. 1993. A 3-D model for the CD40 ligand predicts that it is a compact trimer similar to the tumor necrosis factors. Int. Immunol. 5:233-238.

29. Padayachee, M., R. J. Levinsky, C. Kinnon, A. Finn, C. McKeown, C. Feighery, L. D. Notarangelo, R. W. Hendriks, A. P. Read, and S. Malcolm. 1993. Mapping of the X-linked form of hyper IgM syndrome (HIGM1). J. Med. Genet. 30:202-205.

30. DiSanto, J. P., S. Markiewicz, J.-F. Gauchat, J.-Y. Bonnefoy, A. Fischer, and B. G. de Saint. 1994. Prenatal diagnosis of X-linked hyper-IgM syndrome. N. Engl. J. Med. 330:969-973.

31. Naylor, J. A., P. M. Green, C. R. Rizza, and F. Giannelli. 1992. Factor VIII gene explains all cases of haemophilia A. Lancet. 340:1066-1067.

32. Lakich, D., H. H. Kazazian, S. E. Antonarakis, and J. Gitschier. 1993. Inversions disrupting the factor VIII gene are a common cause of severe haemophilia A. Nat. Genet. 5:236-241.

33. Highsmith, W. E., L. H. Burch, Z. Zhou, J. C. Olsen, T. E. Boat, A. Spock, J. D. Govoy, L. Quittell, K. J. Friedman, L. M. Silverman, et al. 1994. A novel mutation in the cystic fibrosis gene in patients with pulmonary disease but normal sweat chloride concentrations. N. Engl. J. Med. 331:974-980. 